\title{
Avaliação do Programa de Gestão Inter-Institucional Circuito Sul Mineiro de Cafeicultura na Região Sul do Estado de Minas Gerais
}

\author{
Marcelo Márcio Romaniello \\ Robson Amâncio \\ Samuel Carvalho De Benedicto
}

\begin{abstract}
RESUMO
O governo do Estado de Minas Gerais, por intermédio de suas instituições públicas, criou o Programa Circuito Sul-Mineiro de Cafeicultura, na busca dos seguintes objetivos: melhorar a qualidade do café, aumentar a produtividade e reduzir os custos de produção. Entretanto, apesar da importância desse programa como subsídio para a solução de problemas referentes à cafeicultura na região sul de Minas Gerais, ele ainda não foi avaliado. Portanto conduziu-se este trabalho com o objetivo de avaliar o Circuito Sul-Mineiro de Cafeicultura, considerando-se uma abordagem metodológica orientada por diferentes métodos de pesquisa, analisando os objetivos declarados e a sua efetividade quanto aos resultados alcançados. Neste trabalho montou-se um referencial teórico que orientou as perspectivas analíticas contidas na seção de resultados e discussões. Com esta pesquisa, evidenciouse que a combinação de métodos quantitativos (survey) e qualitativos (roteiro semi-estruturado) demonstrou ser uma abordagem adequada e complementar para extrair dados e avaliar o programa em foco. Observaram-se, ainda, evidências de que os objetivos declarados pelo programa foram parcialmente atingidos, baseando-se nas percepções dos cafeicultores, que são os usuários diretos do Programa.
\end{abstract}

Palavras-chave: gestão social; coordenação interinstitucional; agronegócio café; programas públicos; desenvolvimento rural.

\begin{abstract}
The state of Minas Gerais, Brazil, government by mean of its public institutions created the Southern Minas Gerais Circuit of Coffee Culture program in the search for the following objectives: to improve the quality of coffee, increase yield and reduce production costs. Nevertheless, in spite of the importance of this program as a subside to the solution of problems related with coffee culture, it has not been evaluated yet. Therefore, this work was conducted with the purpose of evaluating the Southern Minas Gerais Circuit of Coffee Culture, taking into account a methodological approach guided by different research methods, surveying the stated objectives and its effectiveness concerning the reached results. In this work, a theoretical referential based which guided the analytic perspectives contained in the section of results and discussions was accomplished. By this research work, it was stressed that the combination of quantitative (surveys) and qualitative (semi-structured norm) proved to be a adequate and complementary approach to extract data and to evaluate the program under focus. Further, evidence that the objective stated by the program was partially attained, by basing upon the coffee growers, perceptions who the direct users of the Program.
\end{abstract}

Key words: social management; intersinstitutional coordination; agribusiness coffee; public programs; rural development. 


\section{INTRODUÇÃO}

A região sul de Minas Gerais é a maior produtora de café do Estado e do Brasil, respondendo por $51,5 \%$ da produção mineira e $26,8 \%$ da produção nacional. Seu parque cafeeiro abrange 37.000 propriedades em uma área cultivada de $629 \mathrm{mil}$ hectares, com uma produção média de 12,7 milhões de sacas de café beneficiado. No aspecto social, a cafeicultura sul-mineira representa uma expressiva capacidade de absorção de mão-de-obra, pois gera 672 mil empregos diretos e indiretos e constitui importante fonte de renda para os produtores rurais (Companhia Nacional de Abastecimento, 2003).

Visando à manutenção de destaque da cafeicultura sul-mineira no cenário nacional, o Estado de Minas Gerais, por meio de suas instituições públicas, criou um programa de desenvolvimento regional que constitui como o canal formal para a transferência e difusão de informações, inovações e tecnologias provenientes dos estabelecimentos de pesquisa, ensino e extensão, para atender aos principais problemas referentes à cafeicultura regional.

Com esse objetivo, foi implantado, a partir do ano de 2000, o Circuito SulMineiro de Cafeicultura, que tem como finalidade sistematizar e organizar encontros na área de cafeicultura na região, integrando as instituições públicas de pesquisa, ensino, extensão, instituições privadas e os cafeicultores, na busca dos seguintes objetivos: melhorar a qualidade do café, aumentar a produtividade e reduzir os custos de produção (Felipe \& Abrahão, 2002).

Segundo os organizadores do Circuito Sul-Mineiro de Cafeicultura, a viabilização do evento tem permitido o envolvimento dos recursos físicos, humanos e materiais de instituições como a Empresa de Assistência Técnica e Extensão Rural de Minas Gerais (EMATER-MG), a Empresa de Pesquisa Agropecuária de Minas Gerais (EPAMIG), o Instituto Mineiro de Agropecuária (IMA), a Universidade Federal de Lavras (UFLA) e instituições privadas, proporcionando benefícios aos envolvidos, aumentando a visibilidade dos parceiros, com a divulgação dos eventos, além de possibilitar alcançar os objetivos propostos pelo programa de difusão de tecnologia de coordenação interinstitucional.

Hoje, essas novas formas de arranjos institucionais entre organizações do próprio Estado e organizações privadas constituem iniciativas e modelos de gestão em decorrência da escassez de recursos financeiros internos e externos destinados às instituições governamentais e da transformação da relação Estado-Sociedade na prestação de serviços públicos de qualidade. Além disso, ocorre também uma 
forte mobilização social, que passou a exigir delas maior sintonia com as demandas dos usuários dos serviços públicos, pois é crescente a idéia de que, para a obtenção de resultados, há uma consciência em desenvolvimento, segundo a qual as organizações são complementares e a articulação entre elas é imprescindível, porque, quando somam suas potencialidades, oferecem serviços mais adequados e com maior efetividade.

No campo social, essas integrações envolvem parcerias na administração de programas voltados para o desenvolvimento social e econômico. Em decorrência dessas iniciativas, amplia-se o leque de diferentes agentes no processo de gestão social e surgem outras formas administrativas emergentes na transformação do ambiente físico, socioeconômico e na dinâmica do espaço social, coordenadas pelos órgãos estatais.

Essas coordenações de programas interinstitucionais, sendo também uma busca por soluções, apresentam problemas para alcançar suas metas. As tentativas de reforma na atuação institucional, de modo geral, fracassam, visto que nem sempre coincidem os objetivos dos diversos parceiros que, algumas vezes, podem ser antagônicos. Portanto há que se avaliar se as ações inter-relacionadas das instituições estão dirigidas para a consecução dos objetivos negociados e declarados e se contribuem realmente para o desenvolvimento, no caso, o rural.

A demanda por avaliação de programas interinstitucionais é observada, à medida que se procura aperfeiçoar tanto a elaboração quanto a execução desses tipos de programas. Essa tendência tem-se manifestado pela crescente necessidade que os programas estão enfrentando para justificar as suas finalidades e responder aos freqüentes questionamentos sobre a contribuição que estão dando à solução de problemas, principalmente aqueles relacionados à promoção da mudança social e aumento de renda econômica. Afora esses aspectos, existem aqueles que envolvem a alocação e a administração de recursos financeiros e o custo de oportunidade que representam para a sociedade, ampliando-se e aprofundandose os sistemas de prestação de contas. As propostas de gestão pública e social devem ser avaliadas, principalmente se estão sendo exercidas com efetividade, eficácia e eqüidade.

Dentro dessa perspectiva de discutir o auxílio da avaliação na gestão de programas interinstitucionais e analisar a efetividade das ações para o desenvolvimento rural é que se delimita o problema de estudo. Em contrapartida, avalia-se um programa específico, procurando torná-lo duradouro e que possa contribuir cada vez mais com ações que auxiliem efetivamente o desenvolvimento da cafeicultura na região sul de Minas Gerais. 
Com este trabalho também se procura oferecer aos organizadores do Circuito Sul-Mineiro de Cafeicultura informações sobre a maneira pela qual esse programa de desenvolvimento rural vem sendo conduzido e, com base nessas averiguações, poder oferecer-lhes subsídios para a sua melhoria e retroalimentação, avaliando os objetivos propostos e os resultados alcançados.

Assim, em face da importância deste estudo para uma região onde a cafeicultura tem relevância social na geração de empregos ou como fator de fixação de mãode-obra no meio rural, além de se constituir como importante fonte de renda e da ausência de trabalhos relacionados com avaliação de programa de desenvolvimento rural, buscou-se, por meio desta pesquisa, analisar o Circuito Sul-Mineiro de Cafeicultura, pela identificação e compreensão das atitudes dos organizadores, patrocinadores e do comportamento dos cafeicultores em relação a esse programa.

\section{Objetivos do Estudo}

\section{Geral}

Avaliar o Circuito Sul-Mineiro de Cafeicultura como uma ação pública de desenvolvimento rural de coordenação interinstitucional para a região cafeeira do sul de Minas Gerais. Pretende-se contribuir com a construção de conhecimentos e reflexões em torno da gestão de programas para o desenvolvimento rural, mediante uma abordagem metodológica de avaliação orientada por diferentes métodos de pesquisa.

\section{Específicos}

- Avaliar os macroobjetivos do programa Circuito Sul-Mineiro de Cafeicultura, por meio das percepções dos cafeicultores.

. Discutir a efetividade desse programa em relação aos resultados alcançados.

\section{FundamentaÇão TEÓRICA}

\section{Programas sob Coordenação Interinstitucional}

O Circuito Sul-Mineiro de Cafeicultura é coordenado sob forma de gestão interinstitucional, envolvendo instituições públicas de pesquisa, ensino e extensão, 
para o desenvolvimento do setor rural e instituições privadas da cadeia de produção do agronegócio café. Essas novas formas de arranjos institucionais inserem-se no contexto da escassez de recursos financeiros destinados às instituições governamentais; além de forte mobilização social que passou a exigir delas maior articulação mútua, pois é crescente a idéia de que as organizações são complementares e que, para alcançar resultados positivos, elas deverão somar suas potencialidades e oferecer serviços mais integrados.

A escassez de recursos passa a ser uma questão central, ao limitar a capacidade de resposta do Estado às demandas crescentes na área social. Assim, ao lado da preocupação com a democratização dos processos e com a eqüidade dos resultados, são introduzidas na agenda preocupações com a eficiência, a eficácia e a efetividade da ação estatal, assim como a qualidade dos serviços públicos prestados (Farah, 1998a, 1998b).

Para Reis (2001), essa redefinição da esfera pública inclui a construção de novos arranjos institucionais, que superam o modelo de provisão estatal e o padrão uniorganizacional centralizado. Tais arranjos apontam a construção de redes institucionais que reúnem diversos atores, envolvendo articulações intersetoriais, intergovernamentais e articulações entre Estado, mercado e sociedade civil. Tais redes são constituídas tanto para a formulação de programas como para a provisão dos serviços públicos, que anteriormente eram atribuição exclusiva do Estado. A adoção dessas novas formas de ação do setor público tenta garantir flexibilização gerencial, o que pode contribuir para a obtenção de resultados positivos no que diz respeito à prestação de um determinado serviço ou ao desempenho de um setor.

Segundo Farah (2001), a busca de novas formas de articulação com a sociedade civil e com o mercado pode envolver a participação de ONGs, da comunidade organizada e do setor privado na provisão de serviços públicos e a introdução de novas formas de gestão nas organizações estatais, de forma a dotá-las de maior agilidade, eficiência e efetividade, superando a rigidez derivada da burocratização de procedimentos e da hierarquização excessiva dos processos decisórios.

Entretanto Cohen e Franco (1993) consideram que a administração de programas e projetos sociais de coordenação interinstitucional apresentam problemas especialmente difíceis. As tentativas de reforma administrativa global, de modo geral, fracassam, parecendo mais adequado postular avanços parciais que tendam a conseguir persistência e continuidade nas ações, porquanto, antes de tudo, se devem evitar essas duplicações nas coordenações, porque um dos problemas típicos é a sua descoordenação. Primeiramente, o gerenciamento social entre instituições governamentais são dirigidos por diversas autoridades que nem sempre 
coincidem nos objetivos ou na modalidade de execução e, algumas vezes, podem chegar a ser antagônicas. A própria forma como são distribuídos os recursos conduz à fragmentação das políticas. Diferentes instituições estatais traçam planos e realizam ações separadamente e sem levar em consideração o que estão fazendo outros órgãos do mesmo setor público.

Nesse contexto, é difícil e, freqüentemente, os esforços mostram-se estéreis. Cada organização tenderá a considerar o serviço que presta, e verá as outras mais como potenciais competidoras do que como colaboradoras (Cohen \& Franco, 1993). Tal ponto de vista não é errôneo, ao pensar que os recursos que mantêm todas elas provêm da mesma fonte. Em consequiência, ao aumentar o que se outorga a uma, existe outra que receberá menos, como em um jogo de soma zero, com a conseqüente perda de influência e postos de trabalho.

Esses problemas de coordenação interinstitucional se complicam a partir da inclusão da cooperação público-privada, porque, tradicionalmente, essa idéia esteve marcada por uma distinção clássica, segundo a qual o público se identificava com o Estado e o privado com o mercado. As formas de combinação entre público e privado têm assumido características distintas nos campos das políticas voltadas ao desenvolvimento social e econômico. No campo do desenvolvimento econômico, essas parcerias permitem maior visibilidade dos aspectos públicos e privados nos moldes da distinção clássica. Os instrumentos da permissão, concessão, terceirização, empreitada etc. são exemplos da relação em que se pode distinguir com clareza os interesses, os papéis de cada uma das partes, os objetivos específicos e comuns e a sua materialização nos resultados.

Para a administração, esses novos modelos de gestão tornam-se importantes, pois a interação interinstitucional é, muitas vezes, equivocada. Por exemplo, seria ingênuo pensar que qualquer tipo de articulação resulta em ação mais conseqüente e produtiva dessas atividades. Há que se questionar e avaliar continuamente se as ações relacionadas estão dirigidas para a consecução dos objetivos maiores das atividades e, além disso, se estão contribuindo de forma explícita para o desenvolvimento rural. Superar esses desencontros é difícil, visto que a necessidade de coordenar desemboca inevitavelmente nos problemas de missão e de autoridade para o setor rural. Esses pontos costumam ser pouco visíveis; contudo têm grande impacto sobre a capacidade operativa das políticas sociais.

A emergência de um novo setor, desempenhando funções públicas que antes eram de competência exclusiva do Estado, possibilitou o surgimento de novos arranjos entre o público e privado, potenciando o interesse público na área social. Sua materialização tem-se dado por meio de formas sui generis de articulação, cujo eixo principal é a composição da gestão pública com a gestão privada, notadamente nas áreas sociais, de recursos humanos, financiamento, patrimônio etc. (Reis, 2001). 
Bernareggi (1992) analisou o tipo de gestão interinstitucional chamada Delegada Mista, em que a administração pública e o setor privado participam da gestão, mediante a realização de acordos específicos, que se materializam em estruturas organizacionais específicas, como é o caso do programa de difusão tecnológica Circuito Sul-Mineiro de Cafeicultura.

Uma primeira conclusão deste estudo foi a de que tais formas de gestão implicam a transferência parcial ou total da ação pública estatal para a sociedade civil. Isso permite afirmar que a parceria público-privada pode ser entendida como forma de descentralização, concebida como a transferência de funções, hoje executadas pelo setor público, que poderiam ser mais bem executadas exclusivamente ou em cooperação com o setor privado.

Entretanto Nunes (1997) considera que a inclusão de novos atores da sociedade civil e do setor privado na formulação, implementação e controle das políticas sociais no nível local assinala uma inflexão importante com relação ao padrão de ação do Estado no campo social. De um lado, está havendo uma ruptura com o padrão não democrático de articulação entre Estado e Sociedade, caracterizado pelo clientelismo, pelo corporativismo e pelo insulamento burocrático. Segundo Farah (2001), essas coordenações podem intensificar as práticas clientelísticas.

No caso específico do Circuito Sul-Mineiro de Cafeicultura, a parceria institucionalizada visa sistematizar e integrar as instituições públicas e privadas, proporcionando benefícios aos envolvidos e aumentando a visibilidade dos parceiros com a divulgação dos eventos (EMATER, 2002). Esses novos modelos de gestão tornam-se importantes para a administração, pois a interação interinstitucional é, muitas vezes, equivocada. Por exemplo, seria ingênuo pensar que qualquer tipo de articulação resulta numa ação mais conseqüente e produtiva dessas atividades. Portanto há que se avaliar se as ações do programa de coordenação interinstitucional estão dirigidas para a consecução dos objetivos negociados e declarados e se contribuem realmente para o desenvolvimento rural.

\section{Avaliação de Programas}

A avaliação é uma das fases de qualquer programa de desenvolvimento, que permite identificar distorções durante o processo de sua operacionalização e redirecionar ações para que ele venha alcançar os objetivos propostos. Nesse sentido, Rattner (1979) sugere que a avaliação representa um método de antecipação das repercussões, no meio ambiente natural e social, de aplicação de uma determinada tecnologia, objetivando a maximização de seus efeitos positivos e neutralização dos negativos. Portanto, trata-se de uma técnica de feedback sistemático de informações a ser utilizada no aprimoramento de programas. 
Muitos programas têm como objetivo ocasionar aumentos na produção ou na distribuição de bens e serviços. Tais aumentos podem ser temporários, terminando com o programa. Segundo Cohen e Franco (1993), o objetivo procurado "é a situação que se deseja obter no final do período de duração do programa, mediante a aplicação dos recursos e da realização das ações previstas".

Quando se pensa em avaliar programas de desenvolvimento, é preciso considerar que existem diferentes finalidades ou propósitos associados a essa avaliação. Assim, Sbragia (1984) e Cohen e Franco (1993) consideram que existem diferentes tipologias para avaliação. São elas $\boldsymbol{e x}$-ante; ex-post e de progresso. A primeira é realizada ao começar o programa, antecipando fatores considerados no processo decisório e tem por finalidade proporcionar critérios racionais para uma decisão qualitativa crucial: se o projeto deve ser ou não implantado. A segunda ocorre quando o projeto já está em execução ou já está concluído e as decisões são adotadas, tendo como base os resultados efetivamente alcançados. Já a última tipologia é quando se procura avaliar o programa do ponto de vista de acompanhamento e monitoramento. Essa avaliação de progresso tem como propósito, segundo Sbragia (1984), monitorar o programa durante a sua execução, visando à detecção de problemas e implementação de mecanismos de correção, que devem ser disparados antes que aqueles se tornem críticos.

Com visão semelhante, Quirino (1986) apresenta dois tipos de avaliações: a avaliação de processo e a avaliação dos resultados. A avaliação de processo enfatiza as relações e papéis sociais e as operações e procedimentos que, por suposição, possibilitam o alcance dos objetivos e metas dos programas. As informações sobre esses componentes do processo são obtidas pela explicação dos problemas e possíveis soluções aplicáveis ao programa a ser avaliado, de maneira como são percebidos pelos seus responsáveis e usuários.

Com relação à avaliação dos resultados, Quirino (1986) mostra que há diversas alternativas para se determinar critérios a serem usados. Nesse tipo de avaliação, o que foi conseguido pelos programas é comparado aos seus objetivos e metas, de modo que a diferença ou semelhança entre os dois termos indica o resultado de avaliação.

A avaliação que foi realizada compreendeu as perspectivas da avaliação de resultados declarados, que poderão representar informações de grande valia para a administração do modelo de gestão, institucionalizado pelo programa Circuito Sul-Mineiro de Cafeicultura. Além disso, essa proposta de avaliação poderá ser apropriada pelos organizadores do evento para monitorar e identificar distorções durante o processo e operacionalização e redirecionar ações para que o programa venha a alcançar os objetivos propostos. 


\section{Metodologia}

Neste estudo, a avaliação proposta foi trabalhada com visão ampla das opiniões dos usuários do Programa Circuito Sul-Mineiro de Cafeicultura, sistematicamente aferidas por métodos múltiplos, preocupados, uma vez que elementos em interação nem sempre produzem manifestações mensuráveis, podendo, ainda, alguns desses elementos não apresentar atributos quantificáveis. Portanto foi adotado um procedimento metodológico, incluindo a combinação de dados quantitativos e qualitativos.

Para este estudo, utilizou-se a entrevista estruturada (tipo survey, com questionário e amostragem estratificada) e entrevista de aprofundamento (com roteiro semi-estruturado), como métodos de pesquisa.

\section{Área de Estudo}

O estudo foi realizado em municípios abrangidos pelo Circuito Sul-Mineiro de Cafeicultura, na região cafeeira do sul e sudoeste de Minas Gerais, constituída pelas cidades de Perdões, Formiga, Guapé, Santa Rita do Sapucaí, Três Pontas, Carmo de Minas, Três Corações, Nepomuceno, Cristais, Varginha, Ouro Fino, Alfenas, Coqueiral, Oliveira, Guaxupé, Lavras, Piumhi e Santo Antônio do Amparo.

\section{Seleção dos Atores Sociais}

Os atores escolhidos foram os cafeicultores participantes, considerados públicoalvo do programa Circuito Sul-Mineiro de Cafeicultura.

\section{Amostragem}

\section{Na Pesquisa Quantitativa}

Para a realização das entrevistas estruturadas, utilizou-se uma amostragem probabilística estratificada, em que o universo foi subdividido (estratificado) em grupos mutuamente exclusivos, escolhendo-se uma amostra probabilística simples de cada etapa do evento. A partir desse processo, obteve-se uma amostra de 400 respondentes, o que representa $18,2 \%$ do universo da população formada por produtores de café. 


\section{Na Pesquisa Qualitativa}

Para a definição da amostragem na pesquisa qualitativa, que foi realizada por meio do método entrevista de aprofundamento (tipo roteiro), foi utilizada a amostragem não probabilística por conveniência. Segundo Alencar e Gomes (1998), trata-se de um método em que os indivíduos são escolhidos simplesmente por serem mais acessíveis ou, então, por ser mais fácil a sua avaliação. Sua tipicidade é que interessa ao pesquisador por possuírem alguma vinculação com a realização do programa de difusão de tecnologia em exame.

A população amostrada foi constituída de catorze produtores rurais (cafeicultores), dois presidentes de sindicato dos produtores rurais, dois patrocinadores oficiais, dois extensionistas e um organizador do Circuito Sul-Mineiro de Cafeicultura.

\section{Análise dos Dados}

\section{Na Pesquisa Quantitativa}

No processo de análise dos dados, foi utilizado o software estatístico Statistical Package for the Social Science (SPSS), pelo qual foram avaliados dois tipos de dados estatísticos:

- Análise univariada. Neste tipo de análise utilizaram-se a frequiência, a porcentagem e a média de todas as variáveis consideradas na pesquisa.

. Análise de correlação. Analisaram-se as correlações pelo método de Spermam, com o nível de correlação significante.

\section{Na Pesquisa Qualitativa}

$\mathrm{Na}$ análise das informações obtidas por intermédio de entrevistas de aprofundamento, foram utilizados processos que envolvem a organização das informações em relatos, transcrições, leitura e comparações, para se identificar o que existe ou não em comum, bem como a extração das comparações, dimensões e conceitos e a organização dos conceitos em categorias.

Após as análises dos dados separadamente, eles foram utilizados em uma única redação, em tratamento conjunto na discussão do estudo, apontando a construção de reflexões sobre o programa avaliado.

A adoção dos procedimentos metodológicos deste trabalho teve como objetivo 
experimentar combinações de métodos capazes de fornecer a confiabilidade e validade esperadas, ampliando-se a diversidade de olhares para a estruturação de um plano de avaliação em que está envolvida uma pluralidade de atores sociais e proporcionar uma coleta de dados que represente a compreensão da realidade social implícita.

\section{Resultados e Discussão}

\section{Avaliação dos Objetivos do Circuito Sul-Mineiro de Cafeicultura}

Segundo Garcia (2001), a avaliação deve ser realizada, pois segue o seguinte princípio elementar: não se pode conduzir com efetividade programas e projetos sociais, se os dirigentes não conhecem, de maneira contínua e o mais objetiva possível, os sinais vitais do processo que lidera e da sua situação em que intervêm. Quem não avalia os problemas que deve resolver e o resultado das ações com que pretende enfrentá-los, não sabe o que acontece por conta do seu agir, nem que mudanças provocaram com a sua ação. Portanto a avaliação apresenta-se como requisito imprescindível para o exercício efetivo da gestão. Quem avalia confirma ou corrige, exercendo o poder de dirigir consciente e direcionalmente.

Neste estudo, as frequiências das respostas e as declarações dos cafeicultores, em face das variáveis utilizadas para avaliar o Circuito Sul-Mineiro de Cafeicultura em relação aos seus macroobjetivos propostos, apresentaram resultados que contribuíram para a discussão da efetividade do programa em foco. Dessa forma, apresentam-se esses resultados, a fim de cumprir o objetivo deste trabalho e para melhor compreender a avaliação dos participantes em relação aos resultados alcançados pelo Circuito Sul-Mineiro de Cafeicultura.

\section{Diminuição dos Custos de Produção}

Dos 400 cafeicultores entrevistados, 2,5\% (10) consideraram que as informações apresentadas nos encontros em nada têm contribuído para diminuir os custos de produção; para 45,75\% (183), as informações apresentadas nos encontros pouco têm contribuído para diminuir os custos de produção e para 48,75\% (195), estas informações têm contribuído de fato para diminuir os custos de produção na sua atividade de cafeicultor.

Os dados ainda revelaram uma correlação negativa altamente significativa a $1 \%$, demonstrando que os cafeicultores mais críticos que avaliaram negativamente 
os palestrantes $(-0,302)$ e aqueles que deram menores notas $(-0,240)$ aos Encontros realizados foram também aqueles que indicaram que as informações apresentadas pelo Programa Circuito Sul Mineiro de Cafeicultura em nada contribuiu para diminuir seus custos de produção.

\section{Tabela 1: Diminuição dos Custos de Produção}

\begin{tabular}{cccc}
\hline Respostas & Freqüência absoluta & Freqüência percentual (\%) & \% acumulado \\
\hline Nada & 10 & 2,5 & 2,5 \\
Pouco & 183 & 45,75 & 48,25 \\
Sim & 195 & 48,75 & 97,0 \\
Não responderam & 12 & 3,0 & 100,0 \\
\hline Total & $\mathbf{4 0 0}$ & $\mathbf{1 0 0 , 0}$ & \\
\hline
\end{tabular}

Fonte: dados da pesquisa.

Segundo Garcia (2001), na avaliação podem ser construídos indicadores estabelecidos pelas relações entre as variáveis; assim, são elaborados sinais numéricos no ponto terminal da avaliação-relação entre o indicador obtido em cada momento e o indicador-normal ou enquadramento (adequação) do indicador real na faixa de normalidade estabelecida ou na faixa fora dela. Para os indicadores de resultados que evidenciam as transformações produzidas na realidade social (sobre o público-alvo) por conta da execução do programa, Garcia aponta que a taxa de aprovação (faixa de normalidade) deve ser em torno de $80 \%$ a $90 \%$ e, fora da normalidade, o sinal fora dessa faixa.

Considerando-se que 48,25\% (193) dos cafeicultores respondentes consideraram que as informações apresentadas pelo Programa pouco ou nada estavam contribuindo para diminuir os custo de produção, esse dado apresenta-se fora da faixa de normalidade apresentada por Garcia (2001). Portanto, com base nesses dados, o objetivo proposto pelo Circuito Sul-Mineiro de Cafeicultura apresentase, ainda, pouco efetivo na percepção do cafeicultores entrevistados, pois este objetivo foi parcialmente atingido.

Segundo o cafeicultor, é muito difícil diminuir os custos de produção com os atuais preços dos insumos, como pode ser evidenciado na seguinte declaração.

"Os custos de produção, ah, estão muito difíceis de diminuir. Como você vai deixar de adubar uma lavoura? Se você deixar de adubar, você está perdendo rendimento mais na frente, e como os custos dos insumos estão aumentando, chegou no limite... Infelizmente, não dá para reduzir não; eles podem até falar sobre redução de custo, mas não tenho não" (Produtor 01).

Na perspectiva de outro cafeicultor, as informações repassadas pelo Circuito Sul Mineiro de Cafeicultura contribuíram somente um pouco, porque as tecnologias difundidas não são adaptadas para os pequenos produtores. 
"É, diminuir custo hoje é uma coisa complexa e muito difícil. Indiferentemente, eu acho que tem contribuído um pouco, o resto a gente tem que se virar lá. Porque essa contribuição que tem dado aí muitas vezes não dá para o pequeno produtor. Por exemplo, pouca coisa se falou para os pequenos. Tem havido muita tecnologia e muita atenção para o médio e grande produtor. Para o pequeno, tem ficado a desejar e muito. Se perguntar para o pequeno, ele vai falar a mesma coisa" (Produtor 09).

$\mathrm{Na}$ percepção dos participantes dos eventos promovidos, existem produtores que consideraram que com os atuais preços dos insumos agrícolas e a falta de tecnologias apropriadas para os pequenos cafeicultores não é possível diminuir os custos de produção. Portanto considera-se que tal objetivo deve ser mais bem sistematizado com ações para que ele venha a alcançar o que foi proposto, devendose, portanto, incluir mecanismos de correção para melhorar a efetividade do objetivo procurado pelo Programa.

Com relação a tecnologias apropriadas, os gerentes do Programa devem estar atentos ao considerarem os temas e as tecnologias programadas, pois deverão compreender a visão ampla e compreensiva da forma de vida desses produtores, de suas necessidades e de suas aspirações e objetivos, a curto e longo prazo, fazendo com que as inovações (tecnologias) sejam orientadas para o sistema social verificado (público alvo).

A inovação é apontada por Rogers (1995) como um dos elementos-chave para o processo de difusão de tecnologia. Entretanto esta tecnologia deverá ser problematizada e equacionada pela observação atenta da realidade na qual se identificam os sistemas de produção em uso pelos cafeicultores e uma série de variáveis de ordem social, econômica e cultural que intervêm na produção. Mediante a apreensão da realidade, selecionam-se problemas que estão afetando o processo produtivo e que precisam de solução.

Para Souza (1987), a incorporação efetiva dos produtores e das suas experiências no processo amplo de difusão de tecnologia, vivido pelas agências de desenvolvimento rural (entre elas a pesquisa e extensão), tem o potencial de colocar em outro nível a atual especificação dos modelos de difusão.

Continua sendo fácil compreender a difusão de tecnologia como aquele processo linear: pesquisa $\rightarrow$ extensão $\rightarrow$ produtor. O difícil tem sido compreender o lado inverso do processo, ou seja, no seu aspecto produtor $\rightarrow$ pesquisa e extensão $\rightarrow$ pesquisa. A tarefa de exercitar esse lado pouco trabalhado do processo é um dos maiores desafios para os atuais gerentes de pesquisa e de extensão, assim como para todos os agentes sociais envolvidos. 


\section{Mudança da Qualidade do Café Produzido}

Para 4,25\% (17) dos cafeicultores, a participação nos encontros em nada tem favorecido para a mudança da qualidade do café produzido; 45,5\% (182) consideraram que a participação nos encontros pouco contribuiu para a mudança da qualidade de seu café e, para 45,5\% (182) a participação nos encontros promovidos pelo Circuito Sul-Mineiro de Cafeicultura fez mudar efetivamente a qualidade do café produzido.

\section{Tabela 2: Mudança da Qualidade do Café Produzido}

\begin{tabular}{cccc}
\hline Respostas & Freqüência absoluta & Freqüência percentual (\%) & \% acumulado \\
\hline Nada & 17 & 4,25 & 4,25 \\
Pouco & 182 & 45,5 & 49,75 \\
Sim & 182 & 45,5 & 95,25 \\
Não responderam & 19 & 4,75 & 100,0 \\
\hline Total & $\mathbf{4 0 0}$ & $\mathbf{1 0 0 , 0}$ & \\
\hline
\end{tabular}

Fonte: dados da pesquisa.

Nas avaliações feitas pelos cafeicultores, pode-se notar que 49,75\% (199) dos produtores consideraram que a participação nos eventos nada ou pouco contribuiu para a mudança da qualidade do seu produto. Portanto esse objetivo declarado pelo Programa apresenta-se também fora da faixa de normalidade apresentada por Garcia (2001).

Os dados ainda revelaram uma correlação negativa altamente significativa a $1 \%$, significando que os cafeicultores que avaliaram negativamente os palestrantes $(-0,127)$ e deram menores notas $(-0,177)$ aos encontros promovidos pelo Circuito Sul-Mineiro de Cafeicultura são também aqueles que indicaram que esse objetivo em nada contribui para melhorar a qualidade do café produzido. Procurando averiguar, numa perspectiva integrada, outras evidências que podem estar relacionadas às palestras e aos palestrantes, foi encontrada uma correlação altamente negativa na variável: a forma de apresentação dos temas tratados no encontro permitiu sua clara compreensão $(-0,261)$. Isso indica que os cafeicultores que avaliaram negativamente as palestras e os palestrantes foram aqueles que também avaliaram negativamente a sua clara compreensão nos temas tratados pelos encontros promovidos pelo Circuito Sul Mineiro de Cafeicultura.

Esta evidência pode estar relacionada à utilização de vocábulos e terminologias pelos palestrantes, dificultando o bom entendimento das palestras, havendo problemas na comunicação, já que a linguagem utilizada não é a mesma entre o difusor da tecnologia e o público-alvo, como foi declarado pelo cafeicultor que considerou: 
"Tinha que falar numa linguagem mais acessível... porque se sabe que o cafeicultor não tem tanta cultura assim para absorver certos tipos de palavreado que tem. Tem que fazer alguma coisa assim simples, falar uma coisa mais simples para todo o mundo absorver aquilo ali e dar continuidade" (Produtor 13).

É importante observar que um dos princípios da comunicação humana é o de que a troca de idéias ocorre mais facilmente entre indivíduos que são similares, pois os indivíduos pertencem aos mesmos grupos, aos mesmos círculos sociais que compartilham os mesmos interesses, crenças ou têm algo em comum que os une (Rogers, 1995).

O que acontece é que, no padrão convencional da difusão de uma inovação, os participantes não são similares. Os agentes que difundem as tecnologias, por serem tecnicamente mais competentes, podem não utilizar a mesma linguagem que o público-alvo (cafeicultor).

Segundo Bordenave (1995), é preciso eliminar os vocábulos fonte e receptor, tanto da teoria como da prática da comunicação. Na verdade, na comunicação, não poderá haver fontes nem receptores e sim comunicadores como protagonistas igualitários, configurando um idêntico processo de interação humana.

\section{Aumento da Produtividade}

Para 4,25\% (17) dos cafeicultores, a sua participação nos Eventos em nada tem favorecido para o aumento da produtividade de sua lavoura, para 43,25\% (173), pouco favoreceu o aumento de sua produtividade e, para 47,75\% (191) dos cafeicultores o Circuito Sul-Mineiro de Cafeicultura contribuiu para o aumento de sua produtividade. Pode-se constatar, portanto, um indicador fora da normalidade, indicando que o objetivo declarado pelo Programa foi parcialmente atingido, ainda, pouco efetivo na percepção dos cafeicultores.

Os dados das análises estatísticas revelaram uma correlação negativa altamente significativa a $1 \%$, indicando que os cafeicultores que avaliaram negativamente os palestrantes $(-0,206)$ e deram menores notas $(-0,198)$ aos encontros promovidos pelo Circuito Sul-Mineiro de Cafeicultura são aqueles que indicaram que esse objetivo nada ou pouco tem contribuído para aumentar a produtividade. Foi encontrada também uma correlação altamente positiva a 1\%, para aqueles cafeicultores que consideraram que as informações apresentadas nos encontros têm contribuído, de fato, para diminuir os custos de produção $(+0,58)$ e a variável que mediu o nível de satisfação em relação à mudança de qualidade do café produzido $(+0,448)$, pois são também aqueles produtores que avaliaram efetivamente que o Circuito Sul-Mineiro de Cafeicultura favoreceu o aumento da produtividade de sua lavoura. 


\section{Tabela 3: Aumento da Produtividade}

\begin{tabular}{cccc}
\hline Respostas & Frequiência absoluta & Freqüiência percentual (\%) & \% acumulado \\
\hline Nada & 17 & 4,25 & 4,25 \\
Pouco & 173 & 43,25 & 47,5 \\
Sim & 191 & 47,75 & 95,25 \\
Não responderam & 19 & 4,75 & 100,0 \\
\hline Total & $\mathbf{4 0 0}$ & $\mathbf{1 0 0 , 0}$ & \\
\hline
\end{tabular}

Fonte: dados da pesquisa.

Nessa variável que mede o nível de percepção do cafeicultor quanto ao aumento de sua produtividade, a avaliação feita pelos cafeicultores foi considerada como fora da normalidade. Portanto ficou evidenciado que este objetivo declarado foi parcialmente atingido, ainda que pouco efetivo nas percepções dos cafeicultores, pois 47,5\% (190) dos cafeicultores entrevistados declararam que em nada ou pouco as informações apresentadas têm contribuído para aumentar a sua produtividade.

Segundo a declaração do cafeicultor entrevistado, o Programa ajuda no aumento da produtividade em sua propriedade rural. Isto pode ser evidenciado na seguinte declaração:

“A produtividade aqui não é problema, mas ajuda sim” (Produtor 02).

Segundo a visão de outro produtor rural, são importantes o aumento da qualidade do café produzido e a diminuição dos custos de produção e não a produtividade para a região sul do Estado de Minas Gerais, pois a produtividade pode elevar mais ainda a crise do preço do café. Isto é observado no seguinte depoimento:

"Acho que é uma faca de dois gumes. Nós estamos nessa situação, penalizados, hoje, por conseguir uma safra recorde, por conseguir uma produção de café que nunca houve no Brasil. Então, estamos sendo penalizados por isso, porque coincidiu com o mundo inteiro produzindo safras recordes. Então, eu acho que um planejamento, uma política definida para a cafeicultura é o que está faltando, e acho que se a gente não tiver uma definição de quantos pés de café vai ser o parque cafeeiro do Brasil, a partir dali vamos aumentar a produtividade por área. Eu acho que é uma coisa que precisa ser feita para diminuir custo, mas aumentar área plantada, incentivar mais café, acho que não é hora mais" (Produtor 03).

É notório que a cafeicultura mundial atravessa, no momento, uma de suas mais acentuadas crises, sendo o preço recebido pela saca de café um dos mais baixos da história da comercialização do produto. O agravamento da crise cafeeira no Brasil é explicada principalmente por aquela que é a mais básica dentre as leis que regem a comercialização de qualquer produto: a lei da oferta e da demanda. Quando um produto é ofertado no mercado além da demanda, o que ocorre é a 
desvalorização e, no caso do café, que é um produto armazenável, gera estoques que poderão ser comercializados ou utilizados posteriormente. Isso ocorreu recentemente, a partir de 1999 até a safra 2002/2003, quando a produção foi além daquelas que o mercado pôde captar, refletindo-se na elevação dos estoques mundiais, principalmente nos países consumidores, o que levou à mais baixa cotação dos preços da história deste produto (Pereira, Bartholo, \& Guimarães, 2004).

Contudo o objetivo do Circuito Sul-Mineiro de Cafeicultura, de aumentar a produtividade dos cafeicultores da região Sul do Estado de Minas Gerais não deixa de ser importante objetivo a ser perseguido pelo programa, pois existem percepções favoráveis e contribuições significativas em relação ao aumento da produtividade para uma boa parte dos cafeicultores entrevistados.

\section{Considerações Finais}

A combinação de métodos quantitativos e qualitativos demonstrou ser uma abordagem adequada e complementar para extrair dados e avaliar o programa Circuito Sul-Mineiro de Cafeicultura e os temas desta pesquisa. Nesse caso, o questionário survey foi um método indispensável, proporcionando dados padronizados sobre características e padrões de comportamento da população. Dados qualitativos, provenientes das entrevistas, foram apropriados para obter uma visão em profundidade dos temas da pesquisa, o que, de outra forma, não seria possível. De fato, a aplicação de entrevistas em profundidade é a melhor maneira de identificar as razões, atitudes e comportamentos humanos, proporcionando aos entrevistados a liberdade de expressar sentimentos e percepções sobre suas realidades, o que não é permitido em perguntas fechadas do questionário. Entretanto estudos de casos demandam tempo; em geral, sua aplicação fica restrita a casos representativos, impossibilitando seu uso para amostra maior. Adicionalmente, é importante ressaltar que, com essa combinação, o pesquisador pode claramente visualizar a interdependência de todos os passos dentro de uma abordagem teórica, discutindo os pontos fortes e fracos dos dados quantitativos e qualitativos. A adoção dos procedimentos metodológicos deste estudo representou um método confiável para o atendimento da problemática e dos objetivos desta pesquisa, pois ampliou-se a diversidade de olhares na qual estava envolvida uma pluraridade de atores sociais, proporcionando uma coleta de dados que representou a compreensão da realidade social implícita.

O Circuito Sul-Mineiro de Cafeicultura tem desenvolvido inúmeras ações para comunicar-se com os cafeicultores da região sul e sudoeste de Minas Gerais, para difundir e transferir informações e tecnologias. Segundo relatório do ano de 
2002, foram realizadas 25 etapas nos diferentes municípios da região, 200 horas de palestras técnicas, 111 municípios se fizeram presentes, com um público total de 8.244 participantes, e média de 330 participantes por etapa. Soma-se a isso um esforço dedicado a publicações e informações escritas e distribuídas, além de cópias de fôlderes e cópias de informativos tecnológicos. Apesar do grande esforço, o Programa ainda não conseguiu atingir efetivamente seus objetivos, porque se verificaram evidências de que os seus objetivos declarados foram parcialmente atingidos, demostrando-se, ainda, pouco efetivos nas percepções dos cafeicultores que são os usuários diretos do Programa em foco.

Finalmente, recomenda-se um teste-piloto para validar e ajustar a abordagem nele contida à realidade do contexto da inovação tecnológica. Espera-se que esse teste possa proporcionar uma frutífera aprendizagem para todos os participantes, incluindo pesquisadores, extensionistas e cafeicultores. Nesse sentido, sugere-se um problema temático a ser extraído de discussões com os diferentes grupos de cafeicultores. Naturalmente, nessas sugestões, está implícita uma preocupação de contexto como um elemento essencial que viabilize a gestão a ser perseguida pelo programa de coordenação interinstitucional Circuito Sul-Mineiro de Cafeicultura.

\section{Artigo recebido em 11.08.2004. Aprovado em 27.10.2004.}

\section{RefERÊNCIAS BibliográfiCAS}

Alencar, E., \&

Gomes, M. A. (1998).

Metodologia de pesquisa social e diagnóstico participativo. Curso de Especialização a Distância: Gestão de Programa de Reforma Agrária e Assentamento. Lavras: UFLA/ FAEPE.

Bernareggi, G. (1992).

Falências do mercado e falências do estado uma introdução. In E. S. Lodovici, G. M. Bernareggi, \& H. Fingermann (Orgs.). Parceria público-privado (Vol. 1). São Paulo: Summus.
Bordenave, J. E. D. (1995).

Além dos meios e mensagens: introdução à comunicação como processo, tecnologia, sistema e ciência (7a Ed). Petrópolis: Vozes.

Cohen, E., \&

Franco, E.

(1993). Avaliação de projetos sociais. Petrópolis: Vozes.

Companhia Nacional de Abastecimento. (2003, dezembro).

Secretaria de Produção e Comercialização, Departamento do Café. Safra - Café: levantamento 2003. Recuperado em 2 junho, 2003, de http://www.conab.gov.br/conabweb/ index.php?PAG=132 
Empresa de Assistencia Técnica e Extensão Rural. (2001).

Circuito Sul Mineiro de Cafeicultura. (Relatório para Discussão Interna). Lavras: Autor.

Farah, M. F. S. (2001, janeiro/fevereiro). Parcerias, novos arranjos institucionais e políticas públicas no nível local de governo. Revista de Administração Pública, 35(1), 119144.

Farah, M. F. S. (1998a)

Reforma de políticas sociais no Brasil: iniciativas recentes de governos estaduais e municipais. In Seminário Internacional Reestruturação e Reforma do Estado: Brasil e America Latina no Processo de Globalização. São Paulo, SP, Brasil.

Farah, M. F. S. (1998b, março).

Reforma de políticas sociais no Brasil: experiências recentes de governos subnacionais. Revista de Administração, 33(1), 33-38.

Felipe, M., \&

Abrahão, E. (2002).

Circuito sul mineiro de cafeicultura. Belo Horizonte: EMATER-MG.

Garcia, R. G. (2001).

Subsídios para organizar avaliações de ação governamental. Brasília: IPEA.

Nunes, E. (1997).

A gramática política do Brasil: clientelismo e insulamento burocrático. Rio de Janeiro: Jorge Zahar Editor.
Pereira, S. P.,

Bartholo, G. F., \&

Guimarães P. T. G. (2004).

Cafés especiais: iniciativas brasileiras e tendências de consumo. (EPAMIG, Série Documentos, 36). Belo Horizonte: EPAMIG.

Quirino, T. R. (1986, abril/junho).

A avaliação de processo na administração de treinamento para a ciência e tecnologia. Revista de Economia Rural, 24(2), 211-234.

Rattner, H. (1979, outubro/dezembro). Avaliação de tecnologia - um instrumento no processo decisório. Revista de Administração de Empresas, 19(4), 79-90.

Reis, M. S. (2001).

Novas formas de gestão dos serviços públicos: a relação público-privado. Recuperado em 15 novembro, 2002, de htxtp://www.tce.sc.gov.br

Rogers, E. M. (1995).

Diffusion of innovations (4th ed.). New York: The Free Press.

Sbragia, R. (1984, janeiro/março).

Avaliação do desenvolvimento de projetos de instituições de pesquisa: um estudo empírico dentro do setor de tecnologia industrial. Revista de Administração Pública, 19(1), 83-93.

Souza, I. S. F. de. (1987, maio/agosto).

Difusão de tecnologia para o setor agropecuário: a experiência brasileira. Cadernos de Difusão de Tecnologia, 4(2), 187-196. 
